\title{
QUIZ AS A TOOL FOR PART COMPLETION EXAM IN ANATOMY
}

\section{Priya P Roy *1, Pratibha P Patil 2, Doshi M A, Ambali M P ${ }^{4}$, Kumar Sai Sailesh ${ }^{5}$.}

${ }^{* 1}$ Associate Professor, Department of Anatomy, Krishna Institute of Medical Sciences, Karad, Maharashtra, India.

${ }^{2}$ M.Sc, Department of Anatomy, Krishna Institute of Medical Sciences, Karad, Maharashtra, India.

3 Professor \& HOD, Department of Anatomy, Krishna Institute of Medical Sciences, Karad, Maharashtra, India.

${ }^{4}$ Professor, Department of Anatomy, Krishna Institute of Medical Sciences, Karad, Maharashtra, India.

${ }^{5}$ Assistant Professor, Department of Physiology, Little Flower Institute of Medical Sciences and Research, Angamaly, kerala, India.

\section{ABSTRACT}

Introduction: Anatomy has always been one of the Basic sciences of Medical sciences. Anatomical knowledge is traditionally tested by means of summative examination, providing information for pass/fail decisions. The present study was aimed to observe effectiveness of anatomy quiz for improvement of academic performance in first MBBS students.

Materials and Methods: After completion of the syllabus for the academic years, students were trained regarding quiz and three quizzes were conducted for students. Participants were requested to give their opinion about the 10 statements pertaining to the Quiz which were conducted in the department of Anatomy.

Results: We have observed positive response from most of the students regarding effectiveness of quiz. Further those who performed quiz very well also performed the same in the university examinations.

Conclusion: Most of the students agreed and supported conduction of quiz in anatomy for better retrieval skills. We recommend further studies in this area to recommend adoption of the quiz in the curriculum.

KEY WORDS: Anatomy quiz, Students feedback, Academic performance.

Address for Correspondence: Dr. Priya P Roy, Associate Professor, Department of Anatomy, Krishna Institute of Medical Sciences, Karad, Maharashtra, India. E-Mail: priyaproy4@gmail.com

\section{Access this Article online}

Quick Response code

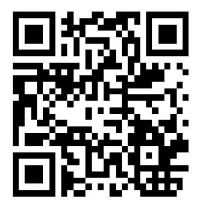

DOI: $10.16965 /$ ijar.2017.124
Web site: International Journal of Anatomy and Research

ISSN 2321-4287

www.ijmhr.org/ijar.htm

Received: 26 Jan 2017

Accepted: 02 Mar 2017

Peer Review: 27 Jan 2017

Published (O): 31 Mar 2017

Revised: None

\section{INTRODUCTION}

Anatomy has always been one of the basic sciences of medical sciences. Anatomical knowledge is traditionally tested by means of summative examination, providing information for pass/fail decisions. Karpicke and Roediger showed that repeated testing produced a large positive effect on long-term retention, while repeated studying had no effect [1]. Quiz is a form of game or mind sport, in which the players (as individuals or in teams) attempt to answer questions correctly. It is a type of formative assessment, the most efficient way to evaluate the students understanding the subject, the content of knowledge gained. Quiz improvises the skills of the students in memo- 
rizing, understanding and also allows an individual to self- assess his/her knowledge in the topic or subject taught. It gives an instant feedback for both teacher in teaching the subject, to analyze what student had understood, what he remembered and learnt in the process and student in getting the concept taught and implicating it when required. Thus, repeated quiz would help both the teacher and the student in improvising the teaching and learning abilities.

In simple terms quiz is a brief assessment to measure the growth in knowledge, abilities and skills in interpreting and analyzing the subject. Quiz enhances the learning skills, helps in reinforcing the existing knowledge or perception of new knowledge, improving the behavioral skills and values. Anatomy can be better understood by using web-based learning modules especially in understanding embryonic development [2]. It also emphasized on the fact that it creates a very positive active learning environment for that students when compared to gigantic lectures [3]. In a study conducted by Jessica, showed repeated tests, quizzes in the medical students in regional anatomy and expanded set of questions in anatomy, had shown a robust improvement from $9 \%$ to $29 \%$ in understanding the subject. The study stated that, quizzes and repeated tests had a positive learning effect and is the most effective strategy learning and retaining the knowledge about human anatomy [4]. The present study was aimed to observe effectiveness of anatomy quiz for improvement of academic performance in first MBBS students.

\section{MATERIALS AND METHODS}

Participants: A total of 211 willing male and female first MBBS students of 2014-15 and 2015-16 batches were included in the study after obtaining voluntary informed consent. The study was approved by institutional ethical committee of KIMS, Karad.

Quiz: After completion of the syllabus for the academic years, students were trained regarding quiz and three quizzes were conducted for students. Each quiz comprises of MCQ questions with negative markings, one line answers and two mark questions. Maximum marks were 50.
Quiz questions were prepared by senior faculty in the department under the supervision of HOD. Quiz questions were projected by using LCD and each student was provided answer sheet to fill the answers for projected questions. At the end of the quiz answer sheets were collected for evaluation. At the end of third quiz feedback was taken from the students by using a questionnaire.

Feedback questionnaire: Participants were requested to give their opinion about the 10 statements pertaining to the Quiz which were conducted in the department of Anatomy.

Each statement should be ranked on five point scale: 5-strongly agree: 4-somewhat agree: 3- Neither agree nor disagree: 2- somewhat disagree: 1-Strongly disagree.

Data analysis: Data was analyzed by SPSS 20.0.

\section{RESULTS}

Results were presented in figure no 1 to 10 . We have observed positive response from most of the students regarding effectiveness of quiz. Further those who performed quiz very well also performed the same in the university examinations.

Fig. 1: feedback of the participants (Data presented are in frequencies).

Quiz are an effective way to study Anatomy.

Q1

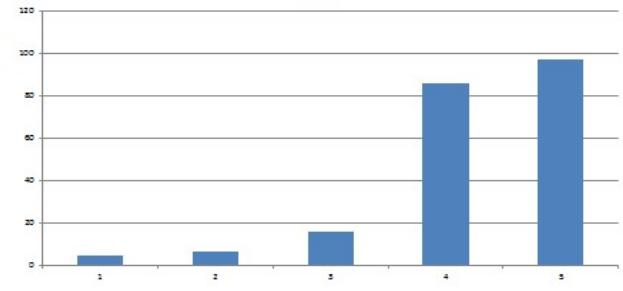

Fig. 2: feedback of the participants (Data presented are in frequencies).

Quiz have motivated you towards self study.

Q2

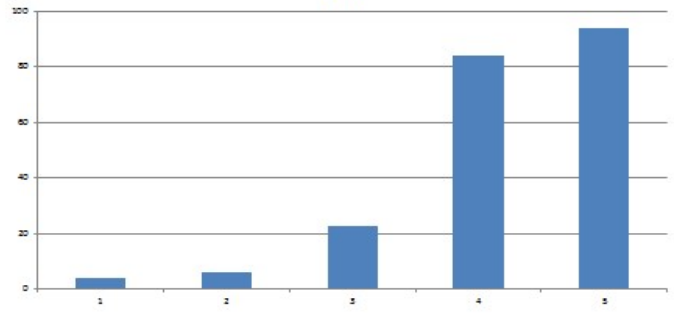


Fig. 3: feedback of the participants (Data presented are in frequencies).

Participating in Quiz improves self learning

Q3

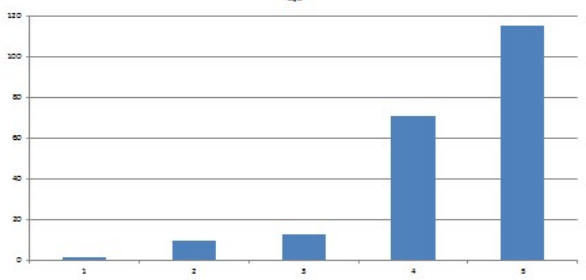

Fig. 4: feedback of the participants (Data presented are in frequencies).

Participating in Quiz enhances teamwork amongst students

Q4

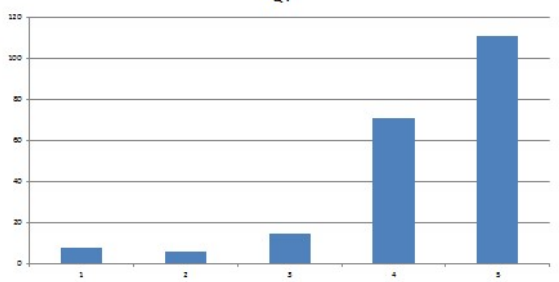

Fig. 5: feedback of the participants (Data presented are in frequencies).

Participating in Quiz helps you to develop time management skills.

0.5

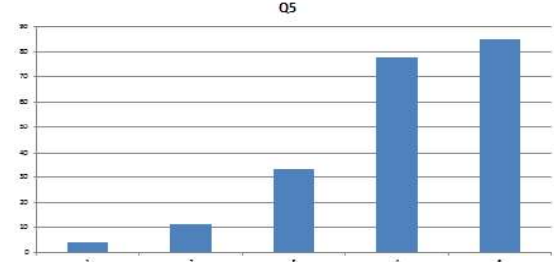

Fig. 6: feedback of the participants (Data presented are in frequencies).

Participating in Quiz has increased your clinical anatomy knowledge

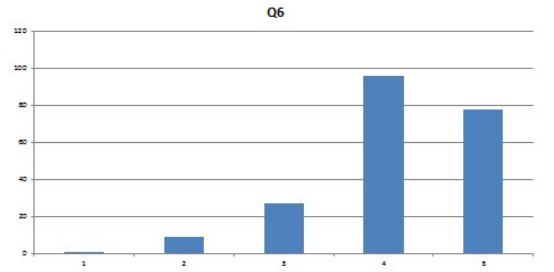

Fig. 7: feedback of the participants (Data presented are in frequencies).

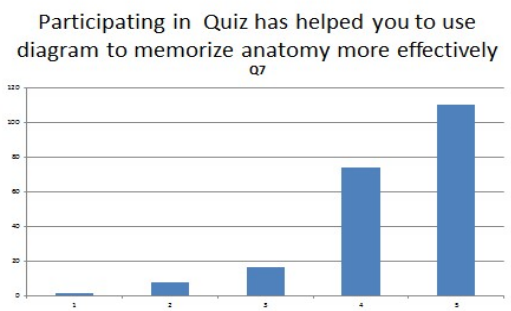

Fig. 8: feedback of the participants (Data presented are in frequencies).

\section{Quiz increase student teacher} interaction.

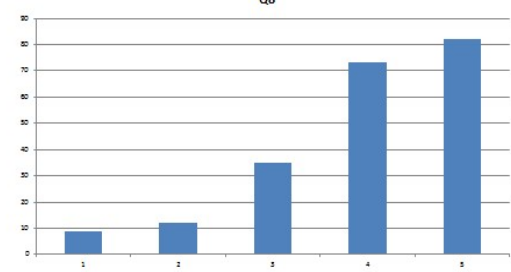

Fig. 9: feedback of the participants (Data presented are in frequencies).

Quiz should be continued in the forthcoming years.

Q9

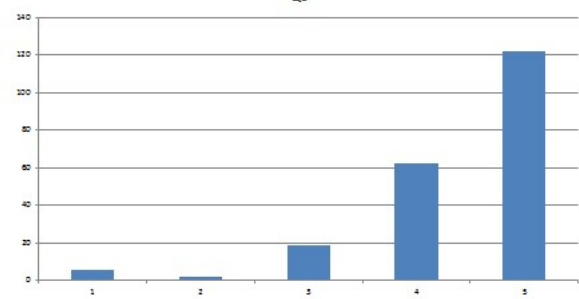

Fig. 10: feedback of the participants (Data presented are in frequencies).

Quiz should be incorporated in the university curriculum

Q10

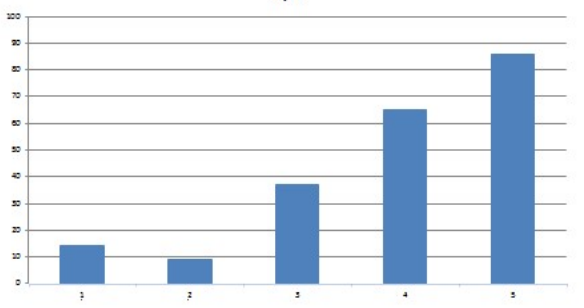

\section{DISCUSSION}

Unlocking wonderment in subjects is essential to the mastery of tests and memory retention, where traditional pedagogy is failing to properly engage the young generation of digital natives, interactive formative assessments during the sessions or learning process and summative assessments after the part completion, might just have the answer to both optimized learning and teaching. Anatomy is the basic medical science subject, that introduces medicine to the students and learning anatomy involves acquiring adoption of skills and attitudes [5]. A well-designed curriculum, teaching and learning activities and assessment methods are essential for better academic performance of the students [6-8]. Inclusion of 
quizzes along with regular assessment methods has been suggested by earlier studies [9]. Quizzes were reported as best tools to encourage and monitor students [10]. Quizzes provide testing effect that is it helps the students to learn and remember the topics for long periods [11-13]. It was proposed that assessment should be voluntary, nonjudgmental and should offer rapid feedback which helps the students for future retrieval of the topics [14-16]. Earlier studies testified that weekly quizzes are more beneficial to improve the academic performance of students [17]. Lucas Stetzik et al., reported that puzzle based learning is more effective than routine teaching methods [18]. Our study agrees with earlier studies as majority of the students participated enthusiastically, and given positive feedback to the quiz and it was reflected in their academic performance as 26 distinctions were obtained in University examinations.

Limitations: Results cannot be generalized as the study was conducted at one institution.

\section{CONCLUSION}

Most of the students agreed and supported conduction of quiz in anatomy for better retrieval skills. We recommend further studies in this area to recommend adoption of the quiz in the curriculum.

\section{Conflicts of Interests: None}

\section{REFERENCES}

[1]. Karpicke JD, Roediger HL 3rd. Is expanding retrieval a superior method for learning text materials? Mem Cognit. 2010;36:116-124.

[2]. Marsh KR, Giffin BF, Lowrie DJ Jr. Medical student retention of embryonic development: impact of the dimensions added by multimedia tutorials. Anat Sci Educ. 2008;1:252-257.

[3]. Bergman EM, Prince KJ, Drukker J, van der Vleuten $\mathrm{CP}$, Scherpbier AJ. How much anatomy is enough? Anat Sci Educ. 2008;1:184-188.

[4]. Jessica M. Logan, Andrew J. Thompson and David W. Marshak. Testing to enhance retention in human anatomy. Anat Sci Educ. 2011;4(5):243-248.
[5]. Smith CF, Mathias H. An investigation into medical students' approaches to anatomy learning in a systems-based prosection course. Clin Anat. 2007;20:843-8.

[6]. Eizenberg N. Applying student learning research to practice. In: Bowden JA, editor. Student learning: research into practice. Parkville: Centre of the Study of Higher Education; 1986. p. 21-60.

[7]. McLean M. Introducing a reward system in assessment in histology: a comment on the learning strategies it might engender. BMC Med Educ. 2001;1:7.

[8]. Mattick K, Knight L. High-quality learning: harder to achieve than we think? Med Educ. 2007;41:638-44.

[9]. Ana Poljièanin, Ana Èariæ, Katarina Viloviæ, Vana Košta, Maja Marinoviæ Guiæ, Jure Aljinoviæ, and Ivica Grkoviæ. Daily Mini Quizzes as Means for Improving Student Performance in Anatomy Course. Croat Med J. 2009 Feb;50(1):55-60.

[10]. Fenderson BA, Fishback J, Damjanov I. Weekly miniexaminations (quizzes) based on extended-matching questions as a means for monitoring medical student performance. Croat Med J. 1996;37:283-7.

[11]. Karpicke JD, Roediger HL. The critical importance of retrieval for learning. Science. 2008;319:966-8.

[12]. Roediger HL, Karpicke JD. Test-enhanced learning: taking memory tests improves long-term retention. Psychol Sci. 2006;17:249-55.

[13]. Karpicke JD, Roediger HL. Repeated retrieval during learning is the key to long-term retention. J Mem Lang. 2007;57:151-62.

[14]. Rolfe I, McPherson J. Formative assessment: how am I doing? Lancet. 1995;345:837-39.

[15]. Chan JCK. Long-term effects of testing on the recall of nontested materials. Memory. 2010;18:49-57.

[16]. Butler AC, Karpicke JD, Roediger HL. Correcting a metacognitive error: feedback enhances retention of low confidence correct responses. J Exp Psychol Learn Mem Cogn. 2008;34:918-28.

[17]. Leonieke N. Palmen,corresponding author Marc A.T.M. Vorstenbosch, Esther Tanck, and Jan G.M. Kooloos. What is more effective: a daily or a weekly formative test? Perspect Med Educ. 2015 Apr;4(2):73-78.

[18]. Lucas StetzikEmail author, Anthony Deeter, Jamie Parker and Christine Yukech. Puzzle-based versus traditional lecture: comparing the effects of pedagogy on academic performance in an undergraduate human anatomy and physiology II lab. BMC Medical Education. 2015;15:107.

How to cite this article:

Priya P Roy, Pratibha P Patil, Doshi M A, Ambali M P, Kumar Sai Sailesh. QUIZ AS A TOOL FOR PART COMPLETION EXAM IN ANATOMY. Int J Anat Res 2017;5(1):3625-3628. DOI: 10.16965/ ijar.2017.124 